\title{
Austrian Bone Conference 2018
}

\author{
ABC 2018, 23. bis 24. November 2018, im Palais Ferstel in Wien
}

Wieder einmal konnte sich die österreichische Osteologie international in Szene setzen. Die Nachfolgeveranstaltung der Austrian Conferences on Progress in Bone and Mineral Research, die über viele Jahre von Klaus Klaushofer gestaltet und geleitet worden waren, präsentierte in einem neuen Format aktuelle Daten aus der internationalen, aber auch nationalen Knochenforschung. Für die Gestaltung und die Inhalte waren unter der Leitung von Peter Bernecker, Peter Pietschmann, Hans Dimai und Katharina Kerschan-Schindl nicht nur sämtliche Vorstandsmitglieder, sondern auch Kollegen aus dem Ausland in die Organisation und die Themenauswahl eingebunden.

In diesem Rahmen wurde auch in diesem Jahr der internationale Forschungspreis (International Research Prize) der Gesellschaft zum 11. Mal vergeben; dieses Mal ging der Preis an Michael P. Whyte (USA) für seine Erforschung der Hypophosphatasie und seine Pionierleistungen bei der Implementation einer suffizienten Therapie für diese teils schwer verlaufende kongenitale Erkrankung. Wie immer wurde diese Entscheidung von einer sehr strengen und hochkarätig besetzten internationalen Jury aus den Einsendungen und Bewerbungen ausgewählt.

Hauptziel der $A B C$ war es, eine interaktive Plattform für Kliniker und Kollegen aus der Grundlagenforschung zu bieten, wo anhand der aktuellen Themen Fragestellungen aus Theorie, aber auch klinischem Alltag diskutiert werden konnten.

Key Note Lectures wurden von internationalen Sprechern mit besonderer Erfahrung auf den jeweiligen Gebieten abgehalten, die so auch einen regen Gedankenaustausch zwi- schen erfahrenen Wissenschaftlern und jungen Forschern ermöglichten. Jungen Forschern wurde die Möglichkeit gegeben, im Format von oralen und Poster-Sitzungen unter der Leitung von erfahrenen Vorsitzenden ihre Projekte und deren mögliche Bedeutung vorzustellen und zu diskutieren.

Geprägt wurden die einzelnen Kongresstage durch Vorträgen von Anna Teti (Italien) über das Bone Remodelling und die Pathophysiologie von Knochenerkrankungen, von Cyrus Cooper (GB), einem der obersten Repräsentanten der IOF mit dem Thema Behandlung der Osteoporose und "Closing the Gap", von Georg Schett aus der Universitätsklinik Erlangen mit dem Thema Interaktionen zwischen Immun- und Skelettsystem. Zu guter Letzt referierte Lorenz Hofbauer aus Dresden über Krebs und Knochenstoffwechsel sowie Christina Åkesson aus Schweden über Knochenheilung und die Verankerung von Knochenimplantaten.

"Meet the Professor"-Sessions wurden von Dr. Grillari (Micro RNA in der Knochenforschung), Barbara Obermayer-Pietsch (biochemische Knochenmarker), Peter Bernecker (Kontroversielles und Kalzium- und Vitamin-D-Substitution) und Martina Rauner über Knochenphänotyping abgehalten.

Ein spezielles Satellitensymposium behandelte seltene genetische Knochenerkrankungen: Hier referierten Roland Kocijan und Heinrich Resch auch über ihre Erfahrungen in der Therapie der Hypophosphatasie sowie weitere "Rare Bone Diseases".

Auch den Kollegen aus den CEELändern wurde in einer eigenen CEE Osteoporose Summit Session die Möglichkeit geboten, Vorträge aus ihren Forschungsbereichen zu halten. Diese
Möglichkeit wurde vor allem von Kollegen aus Ungarn und Polen wahrgenommen.

Der sehr festliche und elegante Rahmen und die einmalige Jahrhundertwendeatmosphäre in den geschichtsträchtigen Räumlichkeiten trugen dazu bei, die Stimmung dieses Kongresses nicht nur durch den Inhalt der Vorträge und die angeregten Diskussionen sehr positiv zu gestalten und die ABC 2018 zu einem vollen Erfolg werden zu lassen.

J.Miner.Stoffwechs. Muskuloskelet.Erkrank. 2019.26:23

https://doi.org/10.1007/s41970-019-

0068-3

(c) Springer-Verlag GmbH Austria, ein Teil von Springer Nature 2019

Autor: Prof. Dr. Heinrich Resch
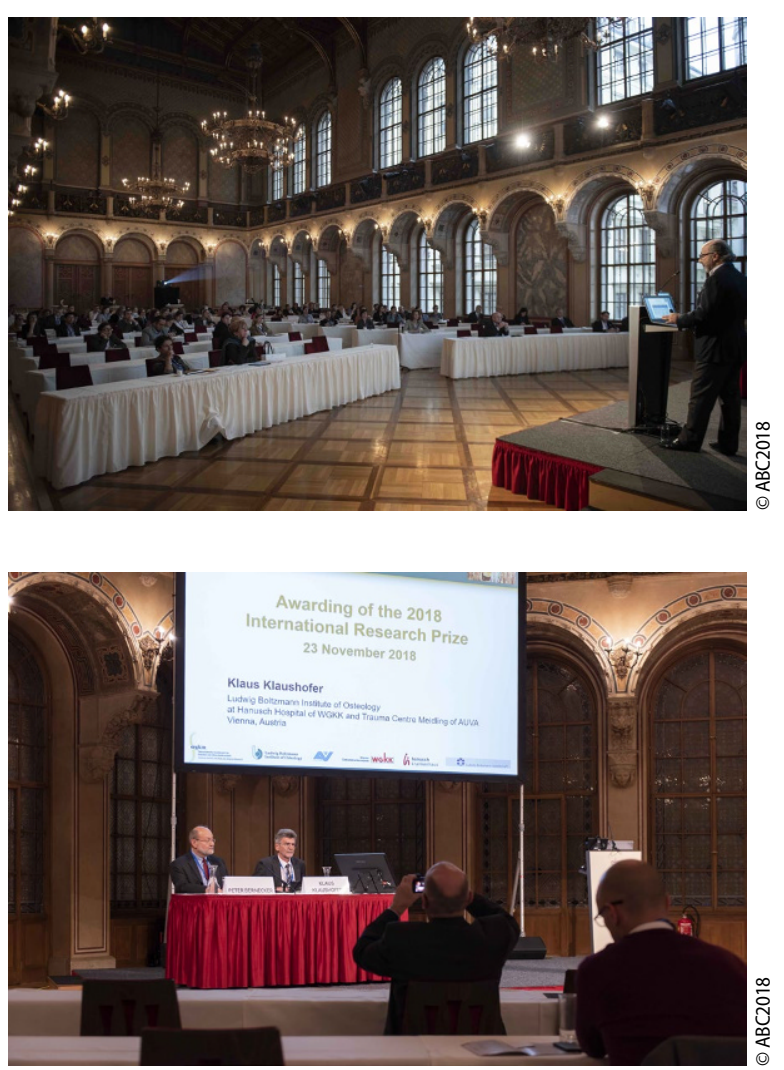